\title{
LOS MECANISMOS PARA LA PARTICIPACIÓN CIUDADANA EN CIUDAD DE MÉXICO: LOS PRESUPUESTOS PARTICIPATIVOS
}

\section{The Mechanisms for Citizen Participation in Mexico City: Participatory Budgeting \\ Os mecanismos para a participação cidadã na cidade de México: os orçamentos participativos}

CASAS CÁRDENAS, Ernesto. Universidad Autónoma de Tamaulipas (México)

ecasas@uat.edu.mx

ÁVILA SÁNCHEZ, Rocío Jazmín. Centro Regional de Formación Docente e Investigación

Educativa (México)

ravila@cretam.edu.mx

\section{Fecha de recibido: 27 de octubre de 2014}

Fecha de aceptado: 14 de abril de 2015

\section{RESUMEN}

La investigación tiene como objetivo general realizar una revisión de las iniciativas sobre participación ciudadana implementadas en Ciudad de México en las últimas décadas y, de manera particular, analizar la iniciativa de los Presupuestos Participativos impulsada recientemente por las administraciones del Partido de la Revolución Democrática (PRD). Para tal efecto se analizan cuantitativamente los resultados de las consultas ciudadanas, que han antecedido a la implementación de dichos presupuestos.

Palabras clave: participación, ciudadanía, presupuestos. 


\section{ABSTRACT}

The research is aimed to develop an overall review of citizen participation initiatives implemented in the City of Mexico in the past decades, and, in particular, to analyze the Participatory Budgeting initiative recently driven by the Democratic Revolution Party's administrations. For this purpose the results of the public consultations, which have preceded the implementation of the Budgeting, are analyzed quantitatively.

Keywords: Participation, citizenship, budgeting.

\section{RESUMO}

A pesquisa tem como objetivo geral realizar uma revisão das iniciativas sobre a participação cidadã implementadas na Cidade de México nas últimas décadas e de forma particular, analisar a iniciativa dos Orçamentos Participativos impulsada recentemente pelas administrações do Partido da Revolução Democrática (PRD). Para tal efeito, analisam-se quantitativamente os resultados das consultas cidadãs, que têm antecedido à implementação de ditos orçamentos.

Palavras-chave: Participação, Cidadania, Orçamentos.

\section{Introducción}

Si bien desde 1997 cuando por primera vez el PRD accedió por la vía electoral al gobierno de la Ciudad de México ${ }^{1}$ y hasta la fecha, se ha concretado una política de participación ciudadana respaldada por una ley y un andamiaje institucional específicos, simultáneamente han prevalecido resistencias en las autoridades locales a delegar y transferir decisiones relevantes a los Comités Vecinales, órganos de representación de los residentes que fueron concebidos con un carácter consultivo.

Asimismo cabe puntualizar que esta política pública no fue innovada por el PRD, pues a lo largo del siglo XX y a iniciativa de los gobiernos designados por el Presidente de la República, invariablemente del Partido Revolucionario Institucional (PRI), en la capital del país se ensayaron diversas formas de representación vecinal y para la participación ciudadana.

Empero, habría que establecer como rasgos distintivos de dichas políticas impulsadas por las administraciones del PRD, que han sido sustentadas en un marco jurídico ex profeso, en instituciones y recursos amplios, así

1 Ciudad de México es la capital del país y el Distrito Federal (DF) donde se asientan los poderes de la Unión, cuyo titular electo de manera directa por la ciudadanía es denominado Jefe de Gobierno. Está dividida en 16 Delegaciones Políticas, sus ejecutivos asimismo electos se denominan Jefes Delegacionales. 
como en un discurso a través del cual se ha pretendido exaltar el tema y lo realizado alrededor de él; lo que en conjunto debería arrojar resultados significativos en cuanto a la consolidación de algún mecanismos para la participación, materializado en una intervención directa, amplia y efectiva de la ciudadanía y de las organizaciones de la sociedad civil al menos en la definición de la agenda pública; cuya comprobación constituye el objetivo general de la presente investigación.

Partiendo entonces de la hipótesis de que las decisiones sobre el diverso y complejo mosaico que constituye la ciudad capital, siguen en gran medida centralizadas en los Jefes Delegacionales y, en última instancia, en el Jefe de Gobierno, cabría observar que a pesar del cambio de partido político en el gobierno local, pervive el carácter asistencial y patrimonialista de la política social, cuyas réplicas en el ámbito de la participación ciudadana se han evidenciado en una sistemática convocatoria a la población para integrarse a los programas en cuestión, más que a participar en su definición, implementación y evaluación, de lo cual no han estado ajenos los intereses electorales de los partidos.

En esa tesitura y con base en investigaciones preliminares (Álvarez, 2006; Bolos, 2006; Cansino, 2006; Sánchez, 2007; Sandoval, 2006; Zermeño, 2004; Ziccardi, 2006), es factible anticipar la constante en torno a que las políticas de participación ciudadana impulsadas por el PRD en el DF, se han circunscrito a una concepción elemental de atención ciudadana, acotadas por ende a la presentación de quejas y sugerencias de la ciudadanía a la autoridad; soslayando tanto el valor de la intervención efectiva de la ciudadanía en la definición del rumbo de la ciudad, como de la organización social que permita cimentar un amplio tejido asociativo de carácter cívico.

De igual forma, se podría inferir que la precaria implicación de los capitalinos en los mecanismos respectivos durante las cuatro administraciones del PRD a la fecha, es consecuencia de que los resultados de los ejercicios cívicos no han contribuido a disminuir de manera significativa los fenómenos de segmentación y exclusión ni las desigualdades sociales en la Ciudad de México.

De cara a este contexto local, a continuación se analizarán los resultados en torno al mecanismo de los Presupuestos Participativos, que ha venido impulsando el PRD hasta ahora; cuya implementación ha sido precedida por la realización de consultas a la ciudadanía sobre los temas a considerar en dichos Presupuestos, organizadas de igual forma por el propio gobierno de la capital.

\section{El debate sobre participación ciudadana}

La gestación de la democracia participativa desde los años sesenta del siglo XX, habría de encontrar su caldo de cultivo en un contexto internacional caracterizado por sociedades con crecimientos exponenciales, complejas y polarizadas, que albergaban a grandes sectores inconformes con los límites impuestos por la democracia representativa a la acción política del ciudadano, e insatisfechos con los resultados en materia de equidad social del Estado del bienestar.

Desde una perspectiva teórica, entre las corrientes de pensamiento que influirían en la construcción del modelo participativo destaca el republicanismo contemporáneo, en cuanto al valor cívico de la participación del ciudadano en la defensa del bienestar común; el neopluralismo, a partir del cual se reconoció la existencia de múltiples demandas y grupos de presión en conflicto, con recursos y posibilidades de implicación social desiguales, frente a una agenda pública sesgada hacia los intereses de las grandes corporaciones económicas transnacionales; así

\section{7}


como planteamientos afines a la escuela marxista, subrayando la operación de las instituciones públicas y privadas a favor del mantenimiento de la estructura de poder y de privilegios (Franzé, 1996; Held, 2002; Kitschelt, 2001).

De inicio habría que precisar que toda forma de participación ciudadana es por definición política, en tanto su ámbito de acción reside en el espacio público donde los sujetos y sus organizaciones interactúan con los diferentes niveles de gobierno para intentar influir, orientar o modificar la toma de decisiones a favor de intereses colectivos, comunitarios o sectoriales (Cunill, 1991); así como para ejercer algún grado de supervisión y control sobre el quehacer gubernamental, lo que se inscribe en los mecanismos de rendición de cuentas o accountability (O’ Donnell, 1998).

Asimismo, participar en el espacio público implica el ejercicio de un conjunto de derechos garantizados legalmente, como la libertad de pensamiento, de expresión, de tránsito y de asociación, que encuentran su conjugación plena en el concepto de ciudadaníaª el cual asimismo implica un grado de autonomía, de libertad positiva como diría Berlin (1988), de compromiso activo a favor del bien común a través de una deliberación colectiva para la estructuración de la agenda pública y la conciliación de intereses, en una perspectiva de responsabilidad compartida.

Con base en estos presupuestos, el debate sobre la participación ciudadana ha oscilado entre dos vertientes que podrían ser denominadas como: "antiparticipativa liberal-conservadora y democrático-participativa" (Águila, 1996, pp. 31-43). No obstante, ambas posiciones se enmarcan en las premisas teóricas del modelo representativo, constituyen posiciones divergentes en tanto la primera sustenta sus convicciones en el pensamiento liberal clásico, ponderando la conveniencia de marcar límites a la intervención de los ciudadanos en los asuntos del Estado, aunque sin demérito de sus derechos políticos básicos a opinar, organizarse y elegir a los representantes políticos de manera periódica.

Mientras la segunda posición sustentada en ideas afines al republicanismo contemporáneo, alienta una libertad individual y una organización social comprometidas con una extensa e intensa participación de ciudadanos y organizaciones en la construcción de la agenda pública, así como en la propia toma de decisiones de gobierno.

Siguiendo la reflexión de Águila, en torno a la primera vertiente se ubican ideas con aire de familia pluralista, en el sentido de que una participación ciudadana intensa divide a la sociedad y, más aún, que márgenes elevados de participación son muestra de insatisfacción de los ciudadanos con sus autoridades; por ende, es motivo de deslegitimación para estas en detrimento de la estabilidad social y la gobernabilidad.

Confluye aquí una concepción del individuo interesado fundamentalmente en la consecución de intereses particulares, por lo cual se intenta favorecer la participación circunscrita a la emisión del voto para la elección de los representantes políticos, quienes deberán garantizar las condiciones legales e institucionales para que los individuos puedan satisfacer sus objetivos personales; en consecuencia, se opta por desincentivar la participación política al tiempo que se impulsa la profesionalización de esta.

En contraparte, la vertiente democrático-participativa intentaría desarrollar lo que Águila y Held denominan el juicio político ciudadano, mediante el incremento de la implicación de los sujetos en los asuntos relevantes para cada comunidad; asegurando que esta participación genera y fomenta beneficios como: desarrollo humano, hábitos

2 Concepto que refiere a una persona con derechos y obligaciones garantizados legalmente, e inmersa en una comunidad en la que incide de manera racional en la percepción de intereses y en la definición de bienes socialmente útiles (Barber, 1998). 
de interacción y esferas públicas para la deliberación, formación de ciudadanía socialmente comprometida, control democrático y colectivo sobre las decisiones de gobierno, lazos comunitarios, eficacia política y autonomía ciudadana (Águila, 1996; Held, 2002).

En este sentido, es importante observar que la participación ciudadana no solo es vista como un elemento normativo que puede favorecer el desarrollo cívico del ciudadano y de la comunidad en su conjunto, sino como la respuesta práctica de sujetos y colectivos organizados alrededor de demandas concretas; en otras palabras, como la afirmación de movimientos sociales disímbolos reivindicando demandas colectivas diversas, algunas históricamente desdeñadas en los espacios legitimados democráticamente para la deliberación pública.

La experiencia alrededor del modelo participativo permite señalar que ha sido el ámbito municipal donde la implicación de los ciudadanos ha tenido mayores posibilidades de expresión y de alcanzar resultados satisfactorios para sus respectivas comunidades; pues es en el barrio, en la colonia, en el municipio donde los individuos acceden a bienes y servicios de manera diferenciada, lo cual define la calidad de vida en esos espacios. Asimismo, debido a la proximidad que se puede establecer entre representantes y representados.

El modelo participativo a nivel local ha implicado el desarrollo de reformas y procesos institucionales a fin de garantizar un grado de implicación de la ciudadanía en los asuntos de gobierno, así como un nivel de satisfacción de sus demandas específicas; en aras de evitar que su implementación resulte contraproducente al generar falsas expectativas, es decir, frustración colectiva ante la inoperancia e ineficiencia de los mecanismos respectivos.

Asimismo, se ha identificado la necesidad de satisfacer algunas condiciones básicas, como un andamiaje institucional flexible que posibilite la promulgación de un marco regulador y la operación de los mecanismos correspondientes, un sistema accesible de información sobre el quehacer gubernamental, un programa de redistribución de recursos materiales y económicos entre los diferentes colectivos y asociaciones, así como la disposición de medios para la rendición de cuentas.

En congruencia con estos requisitos institucionales preliminares, se podría reconocer la disposición de las diferentes autoridades para aceptar y promover la participación ciudadana cuando:

- Existen mecanismos expeditos para la consulta y el debate público, con la población en general y con la parte afectada en lo particular por la acción de gobierno que se pretende materializar;

- Estas figuras de participación se corresponden con el tipo y la cantidad de población involucrada y afectada por la acción de gobierno.

- La participación tiene un carácter institucional no clientelista ${ }^{3}$ (Ziccardi, 1998, pp. 36-37).

No obstante, es menester tomar en cuenta que en el ámbito de la representación política prevalecen incertidumbres sobre la implementación de los mecanismos en comento, sustentadas en objeciones a la viabilidad y a las repercusiones en materia de estabilidad y gobernabilidad, como ha sido comentado; empero, cabría observar que aún el ejercicio más ambicioso de participación ciudadana, que se haya concretado hasta ahora, no ha implicado desdeñar las atribuciones propias de los representantes políticos, ni tampoco ha supuesto prescindir de los partidos políticos compitiendo por las preferencias ciudadanas, ni de los procesos electorales periódicos, ni de los espacios institucionales legitimados para el debate y la elaboración de las normas jurídicas.

3 Se entiende por esta práctica a la forma en la que la autoridad se relaciona con los individuos y las organizaciones sociales, a través de un intercambio de favores o prebendas de manera discrecional y al margen de la ley, que determina el carácter, los alcances y a los beneficiarios de estos intercambios. 
En la misma tesitura, se ha cuestionado que las formas institucionales de inserción ciudadana en la cosa pública, afectan el grado de responsabilidad exigible a los representantes políticos, pues bajo este esquema se convierte a los ciudadanos en corresponsables de las decisiones; sin embargo, cabe sumar al debate el hecho de que en los escenarios donde se han implementado dichos mecanismos, el mandato sobre la decisión final reservado a los representantes políticos no ha variado.

Incluso, se ha cuestionado que la mayoría de los ejercicios participativos se han impulsado desde la esfera gubernamental, con lo cual las decisiones sobre tiempos, agendas, procedimientos e implicados han dependido en gran medida de la voluntad y las intenciones de los representantes políticos en turno; asimismo, está a debate la endeble institucionalización de los procesos participativos, que estaría afectando su continuidad y limitando sus efectos educadores.

Finalmente, otro aspecto que se ha discutido es la presumible orientación de los mecanismos y sus reglamentaciones para favorecer las opiniones y los intereses de aquellos colectivos con mayor disposición y posibilidad de participar; a lo cual cabría añadir el hecho de que en el seno de dichos instrumentos podría prevalecer una tendencia a potenciar la intervención de los colectivos mayormente organizados y, sobre todo, la de aquellos que simpatizan con la posición de la autoridad en torno al tema a debatir, en detrimento de las posibilidades de intervención de los ciudadanos menos organizados y de los colectivos críticos con la situación social prevaleciente.

Sin embargo, cabría integrar a este debate la apreciación normativa en el sentido del aporte de la estrategia basada en la subsidiariedad del asociacionismo, es decir, en el servicio de infraestructura que las asociaciones pueden ofrecer para la deliberación y construcción del mayor número posible de acuerdos, en contextos contemporáneos caracterizados por las diferencias y los conflictos de intereses (Warren, 2001).

\section{La participación ciudadana durante el gobierno del PRI}

A modo de antecedentes que permitan comprender y contextualizar el tema de estudio en la geografía analizada, se procederá ahora a revisar lo que en los hechos se ha realizado en materia de participación ciudadana en la capital de México. A finales de 1928 y con el propósito de regular el funcionamiento del recién creado Departamento del Distrito Federal (DDF), el gobierno de la nación expidió la Ley Orgánica del Distrito y Territorios Federales ${ }^{4}$, en la cual se reiteró que el gobierno de la ciudad quedaba a cargo de un funcionario nombrado y, en su caso, removido libremente por el Ejecutivo Federal, que se denominaría Jefe del DDF.

En materia de representación vecinal y de participación ciudadana se estableció que el gobierno local se auxiliaría de un órgano denominado Consejo Consultivo de la Ciudad de México (CCCM), debiendo instalarse una instancia similar en cada delegación bajo el nombre de Consejo Consultivo Delegacional (CCD); estos órganos colegiados tendrían facultades para opinar, consultar, denunciar, revisar e inspeccionar acciones de gobierno de acuerdo con las especificaciones de la ley, destacando la atribución del CCCM de revisar la cuenta pública anual del DDF.

4 Al unificar la división territorial de la ciudad en Delegaciones Políticas, la norma que la regularía sería la Ley Orgánica del Distrito Federal, posteriormente reformada en 1928, 1941, 1970, 1978, 1994 y en 1996; mismas que se pueden consultar en la Gaceta Oficial del Distrito Federal. 
En el marco del sistema presidencialista que se venía consolidando en el país, en la capital se habría de arraigar un tipo de participación gremial auspiciado por el propio gobierno federal, proceso que se materializó básicamente en dos vías: mediante la creciente centralización de la toma de decisiones en dichos consejos y a través del control gubernamental sobre las organizaciones gremiales y sectoriales. En ese sentido, en 1941, se estipuló la supresión de los CCD, al reformarse la citada Ley Orgánica (Capítulo Sexto, Art. 64).

En esta reforma se determinó también que el CCCM ya no tendría la facultad de revisar la cuenta pública anual del DDF, argumentando que se duplicaban funciones dado que esa facultad le correspondía a la Cámara de Diputados Federal; asimismo, se le reiteró la prohibición de poseer facultades ejecutivas o decisorias, manteniéndole la de opinar sobre asuntos vinculados con los servicios públicos de la ciudad.

De tal forma, que salvo el CCCM, durante tres décadas los espacios institucionales para la intervención de los habitantes en la determinación del rumbo de la ciudad fueron prácticamente nulos; hasta que factores como el crecimiento poblacional, la expansión de la zona urbana, la diversificación de intereses y actores sociales, el malestar civil ante la constante violación a los derechos de expresión, información y asociación, así como la demanda de espacios para la implicación efectiva de los residentes en los asuntos públicos, propiciaron que en la década del setenta el Ejecutivo Federal emprendiera un proceso de reestructuración al respecto.

Con la promulgación en 1970 de la Ley Orgánica del DDF se habría de operar un cambio en materia de integración del CCCM, pues de una representación básicamente gremial se habría de transitar a otra con un carácter más vecinal; de modo que el CCCM se integraría en forma mayoritaria con los presidentes de las Juntas de Vecinos (JV), nueva figura de representación que en alguna medida cumpliría funciones similares a las de los CCD.

EI CCCM y las JV serían previstos como órganos de colaboración ciudadana (Art. 19), lo que implicaba que sus propuestas no obligaban en forma alguna ni al Jefe del DDF ni a los delegados (Art. 26); asimismo, se les habría de reiterar la exclusión de facultades ejecutivas o de decisión, reconociéndoles únicamente atribuciones de consulta, información y opinión (Art. 51).

En la concepción de estas instancias de representación vecinal prevaleció la idea de centralizar su operación y garantizar la injerencia de la autoridad en ellas, lo que una vez más se habría de operar tanto por la vía legal como mediante usos y costumbres. Baste señalar al respecto que en las nuevas facultades de los delegados, figuró la de seleccionar entre los más destacados en su demarcación a las personas que podrían integrar las JV (Art. 5), sin precisar los criterios para determinar quiénes cabrían en tal concepto; así como mediar en las relaciones entre las JV y el DDF (Art. 6).

De cara a esta nueva estructura de representación vecinal, de su endeble representatividad y de sus resultados insuficientes en cuanto a la atención de demandas básicas de la población capitalina, así como del paralelo incremento de la desigualdad social en un contexto de creciente complejidad; habría que ubicar la gestación de diferentes formas de organización y movilización urbano-populares, que vieron la luz pública en la misma década del setenta (Álvarez, 1997; Fernández, 1998).

En este sentido, se puede afirmar que en el DF la organización civil y su incursión en el espacio público han estado asociadas, históricamente, con una precaria acción sustantiva de los representantes políticos para atender las necesidades básicas de los representados; en tanto la limitada institucionalización de los procesos para la participación ciudadana y, en su caso, la subordinación de estos a prácticas corporativas y clientelistas, han generado un alto grado de discrecionalidad en la conducción de ellos y desinterés entre los ciudadanos. 
De modo que las insuficiencias, vicios e inoperancia de las instancias referidas, habrían de motivar la creación de otros órganos en cada delegación política, previstos en la Ley Orgánica del DDF promulgada en diciembre de 1978: las Asociaciones de Residentes (AR) y los Comités de Manzana (CM), que se habrían de sumar en orden jerárquico descendente a las Juntas de Vecinos; en la cúspide de esta nueva estructura permaneció el CCCM, constituido como se ha dicho por los 16 presidentes de las JV5.

Al respecto de esta nueva estructura de representación vecinal, con la que el gobierno central pretendió ampliar la representatividad de los órganos vecinales y garantizar la implicación de los residentes en ellas, cabe resumir que hizo más complejo el proceso para acercar las demandas de los habitantes a las diferentes autoridades, a lo cual abonó la conservación de una organización vertical para la toma de decisiones relevantes; sin que los resultados de su operación hubieran logrado revertir las desigualdades sociales referidas.

A inicios de los años noventa, el contexto político en el DF estaría determinado por las negociaciones entre los principales partidos con presencia en la ciudad en torno a la democratización de los procesos políticos, lo cual se había iniciado con la instauración de la Asamblea de Representantes del Distrito Federal, mediante el decreto promulgado el 10 de agosto de 1987; los temas centrales en las negociaciones fueron la elección directa de las autoridades capitalinas, la instauración de un poder legislativo local y la consolidación de instancias para la participación ciudadana.

Como resultado de dichas negociaciones se reformaría el artículo 122 de la Constitución Política en 19936, previendo la figura de los Consejos Ciudadanos (CC); asimismo, se facultó al Congreso de la Unión para expedir el Estatuto de Gobierno para el DF ${ }^{7}$, en el cual se determinarían las bases para la integración de un Consejo de Ciudadanos por delegación política, que debería gestionar acciones y evaluar programas de la administración capitalina.

Consecuentemente y en un afán de contrapesos entre los partidos, la conformación de los CC se realizaría con base en lo que estableciera el Estatuto de Gobierno del Distrito Federal (EGDF), elaborado por el Congreso de la Unión en donde aún gozaba de mayoría el PRI; así como atendiendo lo señalado en la Ley de Participación Ciudadana (LPC), elaborada por la Asamblea de Representantes del DF, en donde la oposición tenía un peso mayor pero insuficiente para frenar reformas.

Empero, el proceso para la conformación de estas instancias cargaría con la desaprobación de los partidos de oposición, producto del desacuerdo entre las fracciones en el interior de la ARDF, donde el PRI aún con mayoría y de conformidad con lo estipulado en el EGDF, habría de imponer las condiciones sobre la organización y los participantes en el proceso; de modo que al ratificarse dichos términos en la $\mathrm{LPC}^{8}$, los partidos de oposición interpusieron un recurso de inconstitucionalidad ante la Suprema Corte de Justicia de la Nación (SCJN), la cual se declaró incompetente para intervenir en cuestiones electorales.

5 Los Comités de Manzana tendrían un presidente, un secretario y tres vocales como mínimo; las Asociaciones de Residentes, con una estructura interna similar a la anterior, se conformarían con los presidentes de cada Comité de Manzana, y las Juntas de Vecinos, organizadas internamente en forma análoga, estarían integradas por los presidentes de las Asociaciones de Residentes.

6 Decreto de reformas y adiciones a la Constitución Política de los Estados Unidos Mexicanos, publicado en el Diario Oficial de la Federación, el 25 de octubre de 1993.

7 Publicado en el Diario Oficial de la Federación el 26 de julio de 1994.

8 Publicada en el Diario Oficial de la Federación el 12 de junio de 1995. 
De tal manera que a lo cuestionable del proceso de elección de los CC en su conjunto, dada la competencia inequitativa, desleal y el propio desempeño de la autoridad electoral, hubo que sumar la baja representatividad de la mayoría de los 365 consejeros finalmente electos; por lo que una vez más un ejercicio de representación vecinal de carácter institucional, fue deslegitimado por los propios partidos políticos, y sobre todo desdeñado por la gran mayoría de los residentes de la ciudad capital.

Salvo algunas excepciones en el desempeño de los efímeros Consejos Ciudadanos, el papel que en general observaban y su poca vinculación con la ciudadanía, originó que finalmente la figura de representación vecinal fuera derogada, primero del EGDF y luego de la LPC en noviembre de 1996, en la víspera de la primera elección directa del Jefe de Gobierno del DF, en la que el PRI habría de perder el dominio que ejerció sobre el gobierno de la ciudad durante prácticamente todo el siglo XX.

\section{La participación ciudadana en el gobierno del PRD}

Con la legitimidad que brindó al PRD el triunfo electoral de 1997 en la capital, la administración previó la creación de una novedosa figura: los Comités Vecinales (CV) que sustituirían a los Consejos de Ciudadanos. Para estos órganos de representación ciudadana, que deberían ser electos en cada colonia, barrio, pueblo o unidad habitacional y renovarse cada tres años, se establecieron en una nueva ley amplias facultades que contrastaban con las que históricamente se habían atribuido a las figuras precedentes: gestionar, supervisar y evaluar las demandas ciudadanas y las respuestas de las autoridades referentes a servicios públicos, modificaciones al uso del suelo, aprovechamiento de la vía pública, programas de seguridad pública y verificación de giros mercantiles, en el ámbito de la respectiva delegación (Arts. 80-83).

La puesta en operación de los CV arrojó en el mediano plazo de la administración en turno resultados poco idóneos para la representación vecinal y, sobre todo, para la participación ciudadana, siendo esto último lo que a final de cuentas pareció ser el móvil fundamental de la iniciativa impulsada por la nueva administración. Sobre el particular habría que destacar el hecho de que, a los CV se integraron en forma mayoritaria los dirigentes vecinales históricos de cada colonia, muchos de ellos formados en las prácticas del clientelismo que fomentó el PRI, quienes habrían de llevar al seno de estos espacios temas ligados a intereses partidistas, lo que contribuyó a inhibir la participación de muchos actores sociales autónomos.

Intentando hacer frente al escenario que en materia de participación ciudadana le heredó la primera administración del PRD, el gobierno siguiente retomó el tema proponiendo la transformación de los CV en instancias con poder de decisión, en palabras del Jefe de Gobierno: "En una cuarta instancia de gobierno con personalidad jurídica, presupuesto propio y atribuciones para aplicar programas de desarrollo social, dar mantenimiento a obras, con mando sobre la policía preventiva para integrar a la comunidad y garantizar la seguridad pública a los ciudadanos".

No obstante, la historia de esta iniciativa se escribiría en un sentido muy diferente: el Jefe de Gobierno propuso a la ALDF una serie de cambios a la LPC en el sentido referido, mismos que fueron integrados en un paquete de

9 Discurso pronunciado por el Jefe de Gobierno, Andrés Manuel López Obrador, el 5 de diciembre del 2000; se puede consultar la versión estenográfica en el archivo de la ALDF. 
reformas que incluía otras de carácter estructural, como la transformación del DF en una entidad de la federación; dado que el paquete en conjunto despertó amplias controversias y que el análisis del mismo era competencia del Congreso de la Unión, donde el PRD no contaba con los votos necesarios para su aprobación, habría de quedar pendiente hasta 2004.

Mientras tanto habría de seguir operando el esquema de representación vecinal y de participación ciudadana impulsado por el primer gobierno del PRD, sin que el modelo lograra cimentarse en el seno de las colonias, barrios, pueblos y unidades habitacionales; frente a esta realidad y con el objetivo implícito de respaldar las aspiraciones presidenciales del Jefe de Gobierno mediante la construcción de una red ciudadana, se intentó llevar a cabo una propuesta paralela.

Se avanzaría entonces en la promulgación de una nueva Ley de Participación Ciudadana ${ }^{10}$, previendo como órganos de representación vecinal en las unidades territoriales a: i) Los Comités Ciudadanos. ii) Los Consejos Ciudadanos. Las novedades de la ley en materia de mecanismos para la participación serían: i) Rendición de Cuentas. ii) Red de Contralorías Ciudadanas. iii) Asamblea Ciudadana.

En los artículos transitorios se señaló que con esta nueva LPC se abrogaba la anterior de 1998, que su reglamento lo debía expedir el Jefe de Gobierno, que la primera elección de Comités Ciudadanos se realizaría el último domingo de abril de 2005 y, que los Comités Vecinales en funciones continuarían hasta la primera elección de aquellos.

No obstante, la primera elección de Comités Ciudadanos que debía celebrarse el último domingo del mes de abril de 2005 no se realizó, pues a principios de 2005 el gobierno del DF echaría marcha atrás y mediante un decreto de reformas a la LPC, se estipuló que la elección se pospondría hasta que en trabajo conjunto de las comisiones legislativas de Participación Ciudadana y de Asuntos Político-Electorales de la ALDF, se acordaran las formas de organización y representación ciudadanas adecuadas al contexto del DF, así como los procesos de elección o integración que no resultaran onerosos para los habitantes de la ciudad (Artículo Séptimo Transitorio). Finalmente, y sin más justificaciones, dos meses después se canceló definitivamente el proceso de elección de los Comités, en tanto se estipuló que su primera elección se realizaría hasta que la ALDF estableciera lo conducente en la LPC (Artículo Cuarto Transitorio) ${ }^{11}$.

De tal forma que entre los antecedentes que contribuyen a explicar la actual operación y los alcances de las instancias para la representación vecinal, así como de los mecanismos para la participación ciudadana, es imprescindible aludir a la falta de acuerdos entre los principales partidos políticos con presencia en la capital, que se ha traducido en la varias veces postergada conformación de los Comités Ciudadanos (CC).

No obstante, el 24 de octubre de 2010 finalmente se llevó a cabo la elección, mediante un proceso que registró una votación total emitida de 655835 votos, la cual representó el 8,9\% de participación de un padrón de más de 7 millones de electores ${ }^{12}$. De esta manera, se eligió a 1700 CC y 40 Consejos de los Pueblos (CP), que por esta ocasión comenzarían sus funciones el 1 de diciembre de 2010 (en lo sucesivo debería ser el 1 de octubre), de conformidad con la Ley de Participación Ciudadana ${ }^{13}$.

10 Aprobada por la ALDF y publicada en la Gaceta Oficial del DF, el 17 de mayo de 2004.

11 Publicado en la Gaceta Oficial del DF, el 13 de julio de 2005.

12 Datos obtenidos del Instituto Electoral del Distrito Federal.

13 Publicada en la Gaceta Oficial del Distrito Federal, el 27 de mayo de 2010. 
A modo de comparación cabe observar que entre agosto y septiembre de 2013 los CC fueron renovados, con una participación ligeramente mayor a la anterior inmediata que alcanzó 880759 votos, poco más del $12 \%$ de la lista nominal de electores; en tanto las Delegaciones Políticas con mayor participación fueron Iztapalapa con $24 \%$ y Gustavo A. Madero con $13 \%$; mientras las que menos participación registraron fueron Milpa Alta con 1\%, Benito Juárez y Cuajimalpa con $2 \%$.

Asimismo, cabe registrar que la votación más copiosa fue la de los adultos entre 40 y 70 años de edad, poco más de la mitad fueron mujeres. Entre las ocupaciones de los integrantes de las fórmulas que participaron en la elección destacan los empleados, las amas de casa y los estudiantes, mientras los menos interesados en ser electos fueron los profesionales, los servidores públicos y la categoría de patrón o empresario.

En el marco de los trabajos que han atendido los Comités Ciudadanos y por ser el objeto de estudio empírico de la presente investigación, habrá que detenerse en el análisis de la figura denominada Presupuesto Participativo, prevista en el Artículo 83 de la LPC vigente; la cual debe estar precedida de una consulta ciudadana mediante la cual se deben definir los rubros en los que se habrá de ejercer el presupuesto respectivo. El Instituto Electoral del DF está facultado para convocar, organizar, desarrollar y vigilar la realización de la consulta.

Como datos significativos hay que registrar que para tal iniciativa se destina el tres por ciento del presupuesto anual de cada delegación, el cual a su vez debe ser dividido entre el número de colonias y pueblos originarios que conforman a cada demarcación. Los rubros a los que se puede destinar el monto total son: obras y servicios, equipamiento, infraestructura urbana, prevención del delito, actividades recreativas, deportivas y culturales.

\section{Presupuestos participativos}

El primer registro sobre Presupuestos participativos refiere a la experiencia en Porto Alegre, capital de Rio Grande Do Soul, en Brasil, cuando en 1988 y tras su victoria electoral el alcalde del Partido de los Trabajadores decidió consultar a los ciudadanos en qué se debían gastar los recursos económicos del erario municipal, de cara a las grandes desigualdades sociales que enfrentaban los habitantes del municipio (Blanco, 2002).

La implementación de los Presupuestos Participativos constituyó una respuesta de la autoridad municipal a la tendencia histórica de centralizar la toma de decisiones, instaurando este mecanismo que debería permitir a la ciudadanía intervenir en la construcción de las decisiones sobre el destino de los fondos municipales, a través de un proceso complejo que comprendía desde asambleas plenarias por distritos y temáticas, un foro de delegados de las asambleas, hasta la realización de un consejo general sobre el presupuesto, que llegó a decidir la asignación hasta del $25 \%$.

En el caso de Ciudad de México este ejercicio participativo fue implementado inicialmente en 2001, de manera informal pues no se disponía de un sustento legal específico, en tres Delegaciones Políticas: Cuauhtémoc, Tlalpan y Miguel Hidalgo; las dos primeras con gobiernos emanados del PRD y la tercera con uno derivado del partido derechista Acción Nacional. En todos los casos la metodología fue inspirada básicamente por la experiencia de Porto Alegre.

A pesar de los esfuerzos organizativos y de la innovación que implicó, en las tres demarcaciones se habrían de enfrentar problemas de continuidad; en Cuauhtémoc solo se desarrolló una vez en 2001, en Tlalpan en tres ocasiones consecutivas a partir de dicho año, mientras en Miguel Hidalgo se implementó en cinco ocasiones ininterrumpidas a partir del mismo año. Un dato que aporta luz sobre la evolución y vigencia del programa, es 
que en todos los casos la participación nunca rebasó el $5 \%$ de los potenciales implicados, siendo en esta última demarcación en la que menos se implicaron los residentes.

Sería hasta 2011 cuando desde el gobierno de la Ciudad se retomó la iniciativa para todas las Delegaciones Políticas, con base en lo estipulado en el Art. 83 de la Ley de Participación Ciudadana para el DF. Para tal efecto se estableció la realización de consultas a la ciudadanía, con el objetivo de identificar las demandas cuantitativamente más significativas para los residentes.

De tal forma que para cada Presupuesto Participativo, cuyo ejercicio es anual, se ha realizado una consulta a la ciudadanía, adoptando los proyectos específicos más votados que son propuestos con antelación por los mismos ciudadanos, y cuya aceptación ha correspondido a la autoridad organizadora bajo la condición de que se circunscriban a los rubros que se establecen en la Ley respectiva, a saber: obras y servicios; equipamiento; infraestructura urbana; prevención del delito, y actividades recreativas, deportivas o culturales.

Cabe destacar que la principal limitante para la viabilidad de los proyectos propuestos por los ciudadanos ha residido en el monto disponible, pues de acuerdo con la Ley solo se destina el $3 \%$ del presupuesto de cada Delegación Política al mecanismos en cuestión, cantidad que además se debe dividir entre el número de barrios, pueblos y colonias que conforman a cada demarcación. Habría que agregar que los proyectos específicos deben cumplir además con viabilidad técnica y jurídica dictaminada por la propia autoridad organizadora.

De acuerdo con la Ley, pueden votar quienes dispongan de credencial oficial, es decir, quienes estén empadronados en el DF; sobre lo cual hay que subrayar que el nivel de participación invariablemente ha oscilado entre el $10 \%$ de los potenciales votantes, esto ha contribuido de manera directa a restar credibilidad y legitimidad al proceso en su conjunto.

Con base en estos antecedentes metodológicos, a continuación se analizan cuantitativamente los resultados de las consultas ciudadanas efectuadas en 2011, 2012 y 2013, para los Presupuestos Participativos que se ejercieron en los años siguientes a cada una de ellas; se anticipa que en cada gráfica solo se muestran los cuatro rubros más votados en cada delegación política, que de hecho coinciden, lo cual permite observar la centralidad en ellos, no obstante que en cuanto a proyectos específicos en cada rubro, en alguna medida se diversifican como se detallará al final de las gráficas.

Gráfica 1. Alvaro Obregón

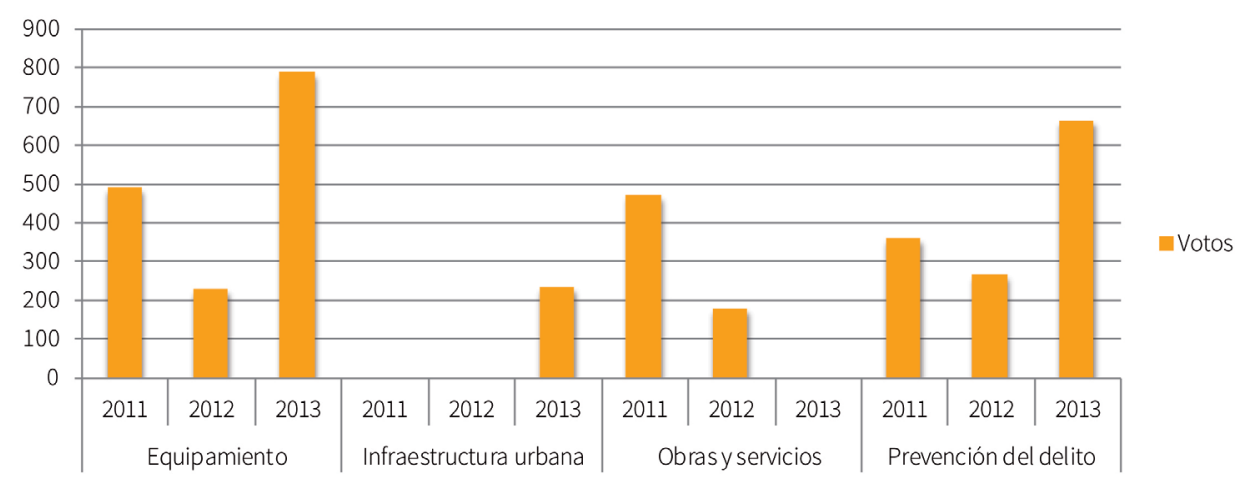

Fuente: elaboración propia con datos del IEDF. 
A lo largo de las tres consultas destacan Equipamiento y Prevención del delito; socioeconómicamente su población mayoritaria es media-baja; es la tercera más poblada.

\section{Gráfica 2. Azcapotzalco}

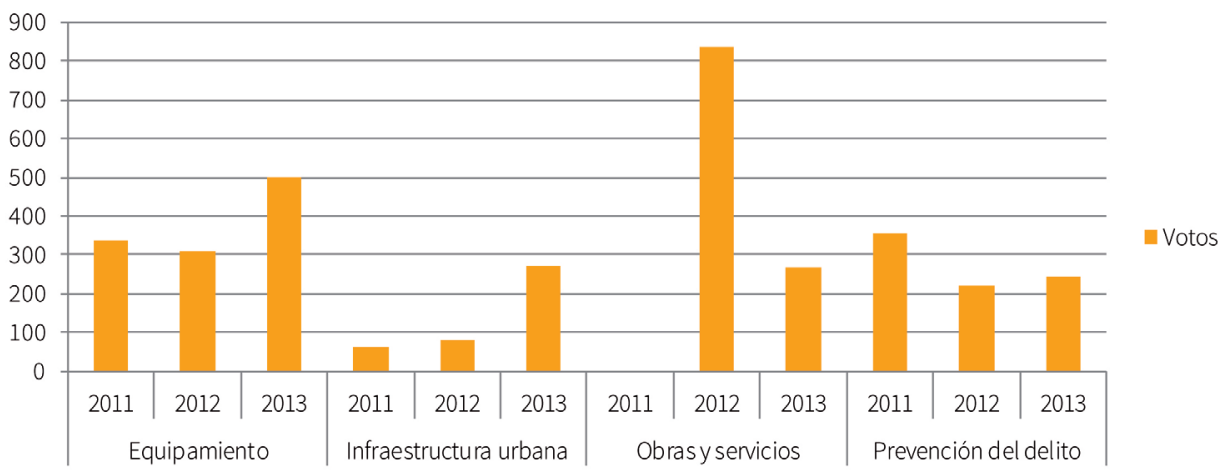

Fuente: elaboración propia con datos del IEDF.

A lo largo de las tres consultas destacan Equipamiento y Prevención del delito, con un pico en Obras y Servicios, socioeconómicamente su población mayoritaria es media-baja.

\section{Gráfica 3. Benito Juárez}

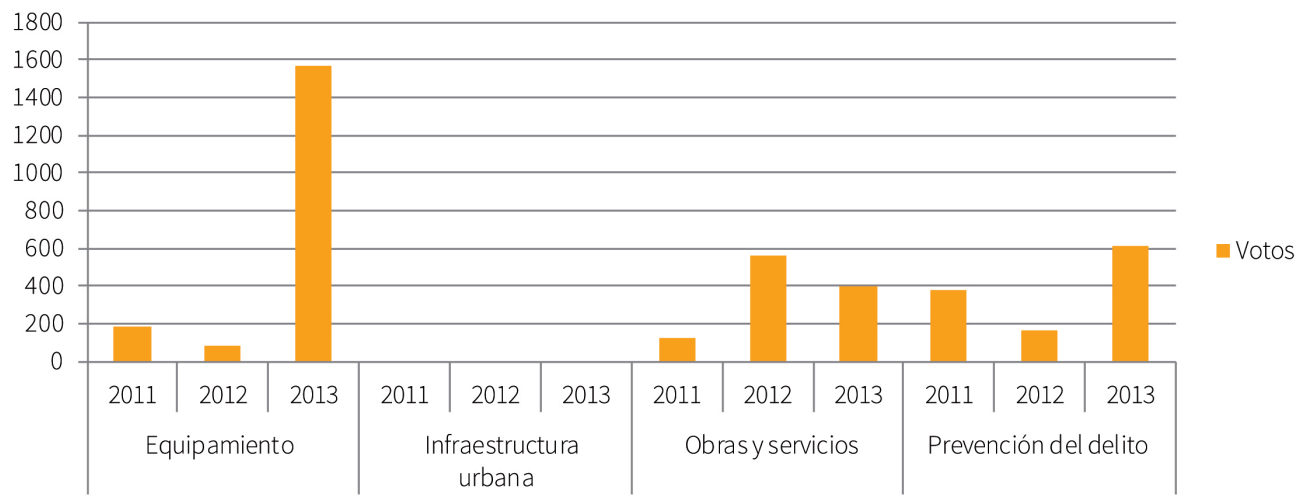

Fuente: elaboración propia con datos del IEDF.

A lo largo de las tres consultas sobresalen Prevención del delito y Obras y servicios; con un pico en Equipamiento, en términos socioeconómicos la población mayoritaria aquí es media-alta y existen amplias zonas del sector servicios. 


\section{Gráfica 4. Coyoacán}

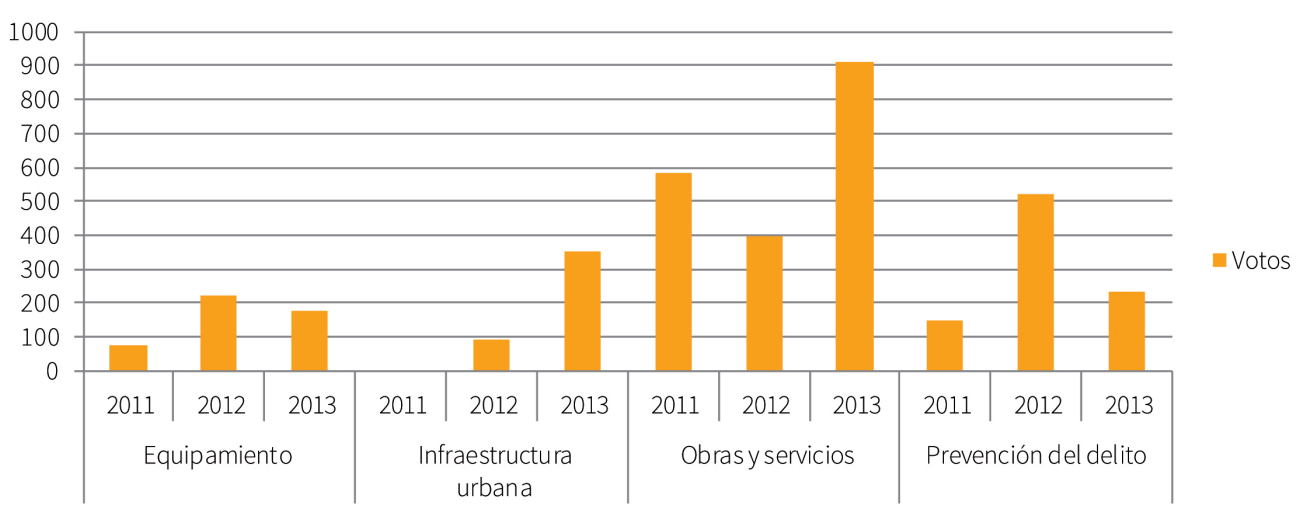

Fuente: elaboración propia don datos del IEDF.

A lo largo de las tres consultas destacan Prevención del delito y Obras y servicios; en términos socioeconómicos, la población mayoritaria es media-alta. Concentra zonas del sector servicios.

\section{Gráfica 5. Cuajimalpa}

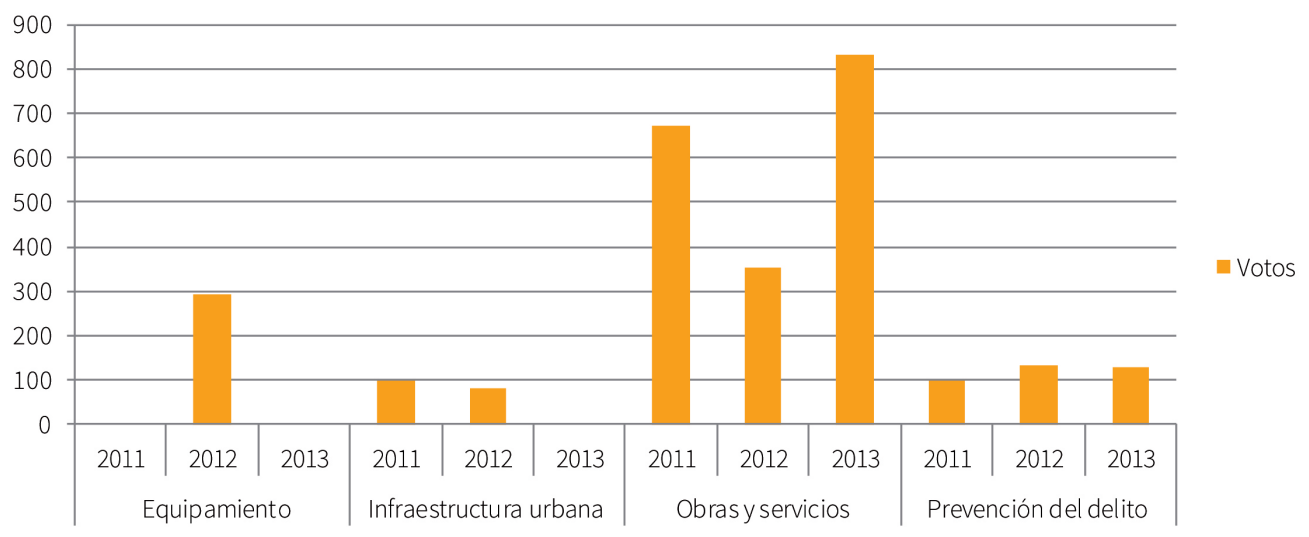

Fuente: elaboración propia con datos del IEDF.

A lo largo de las tres consultas destaca Obras y servicios, seguida de Prevención del delito; en términos socioeconómicos, la población es baja. Hay amplias zonas rurales. 


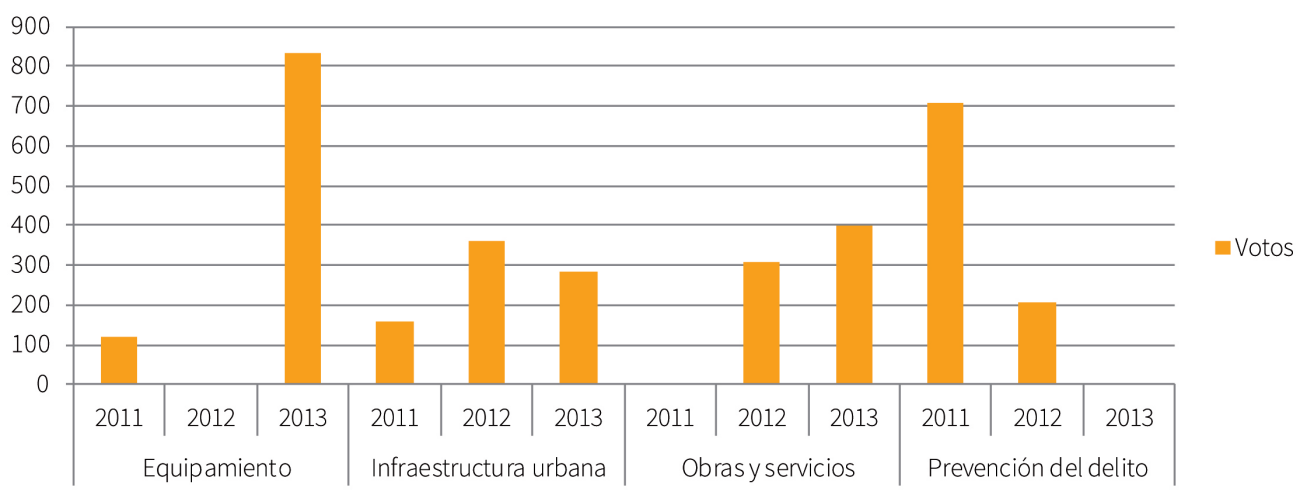

Fuente: elaboración propia con datos del IEDF.

Si bien predominan Obras y servicios e Infraestructura, se observan dos picos en Equipamiento y Prevención del delito. Cabe destacar que su población es muy fluctuante y densa, dado que concentra amplias zonas de oficinas y del sector servicios. En términos socioeconómicos, la población es media-alta.

\section{Gráfica 7. Gustavo A. Madero}

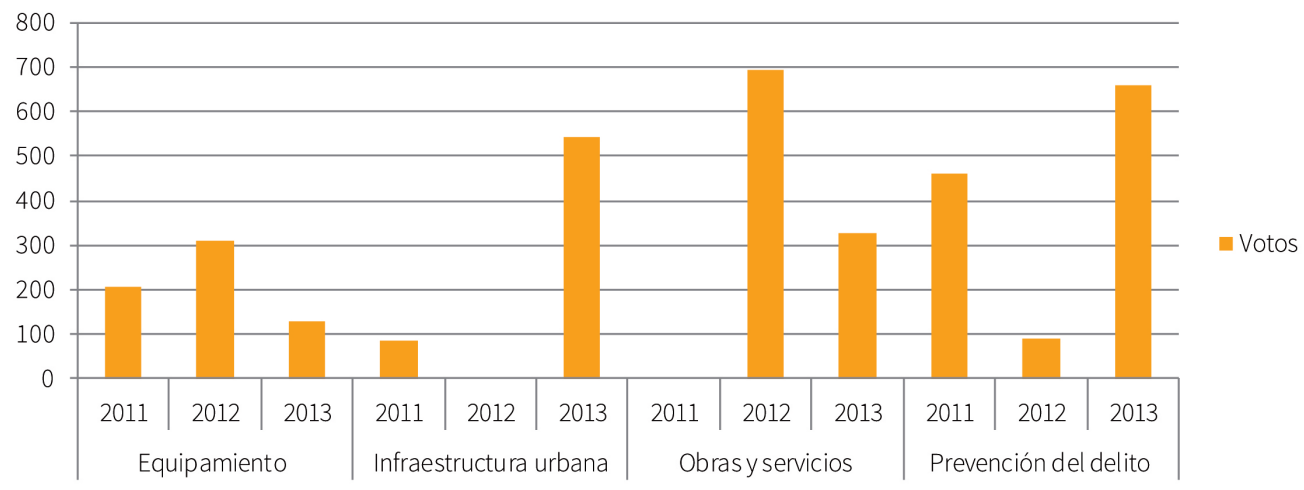

Fuente: elaboración propia con datos del IEDF.

Destacan por su constancia Equipamiento y Prevención del delito, seguidas de Obras y servicios; socioeconómicamente, la población es media-baja. Es la segunda más poblada. 
Gráfica 8. Iztacalco

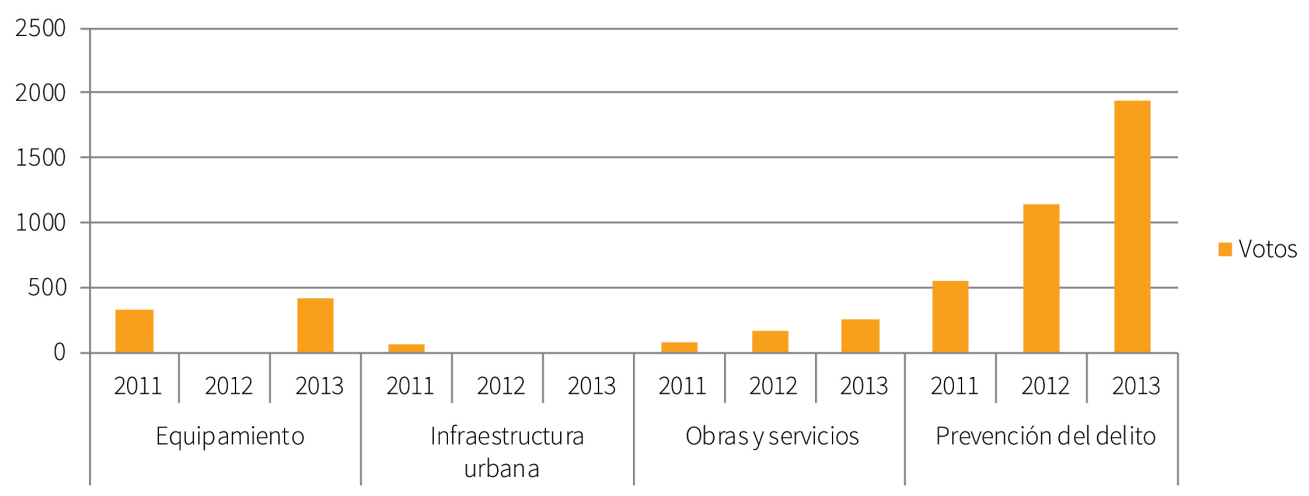

Fuente: elaboración propia con datos del IEDF.

La constante más alta reside aquí en Prevención del delito; en términos socioeconómicos la población mayoritaria es media-baja.

Gráfica 9. Iztapalapa

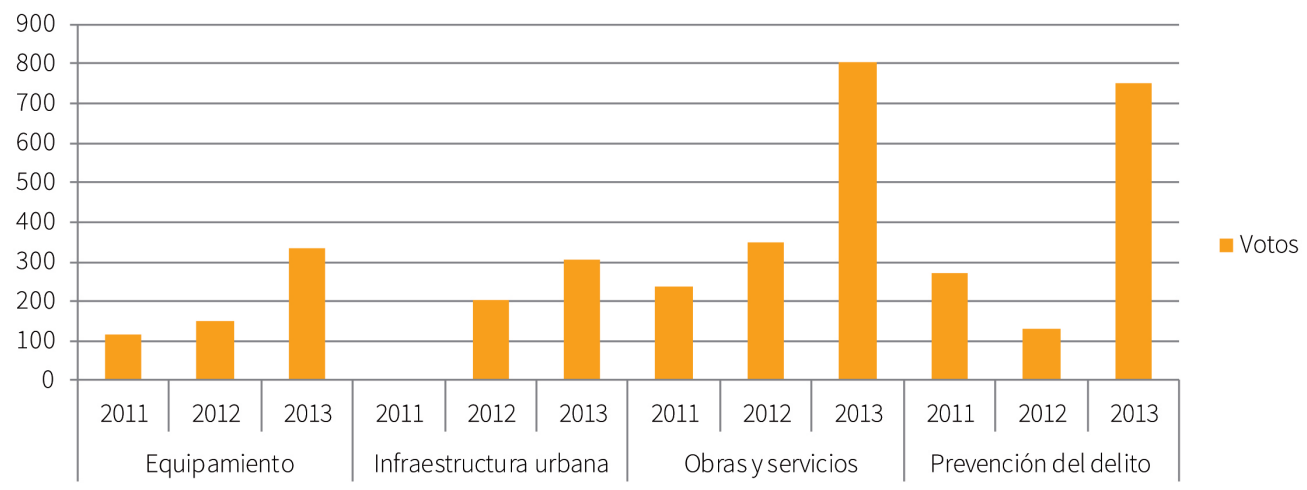

Fuente: elaboración propia con datos del IEDF.

Se puede observar una constante en todos los rubros, con picos en Prevención del delito y Obras y servicios; cabe subrayar que es la delegación más poblada y que en términos socioeconómicos mayoritariamente es baja. 


\section{Gráfica 10. Magdalena Contreras}

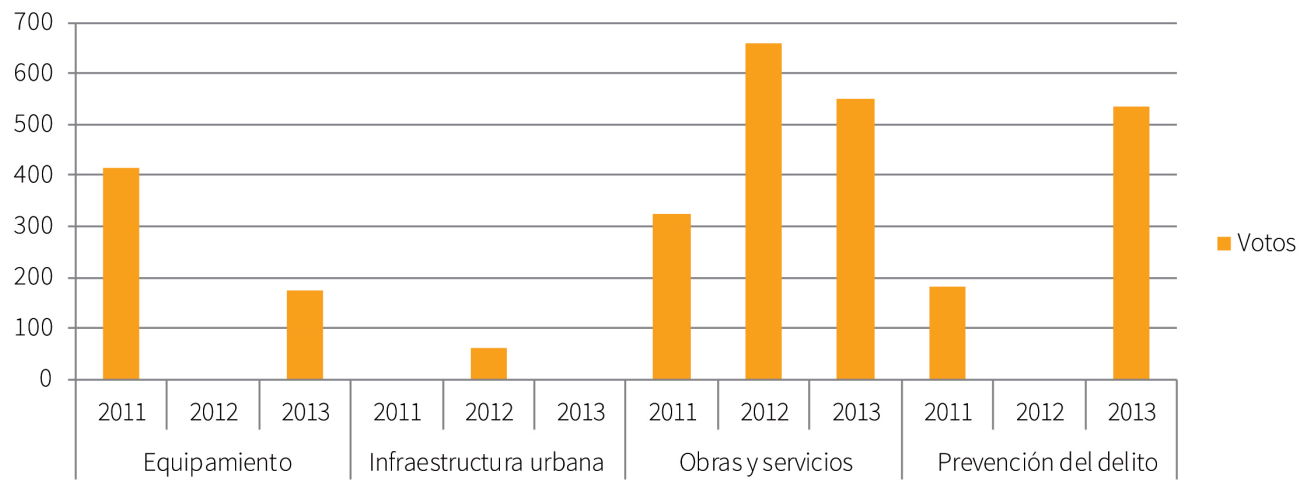

Fuente: elaboración propia con datos del IEDF.

En las tres consultas destaca Obras y servicios; con picos en Equipamiento y Prevención del delito; socioeconómicamente la población mayoritaria es media-baja. Existen zonas rurales.

\section{Gráfica 11. Miguel Hidalgo}

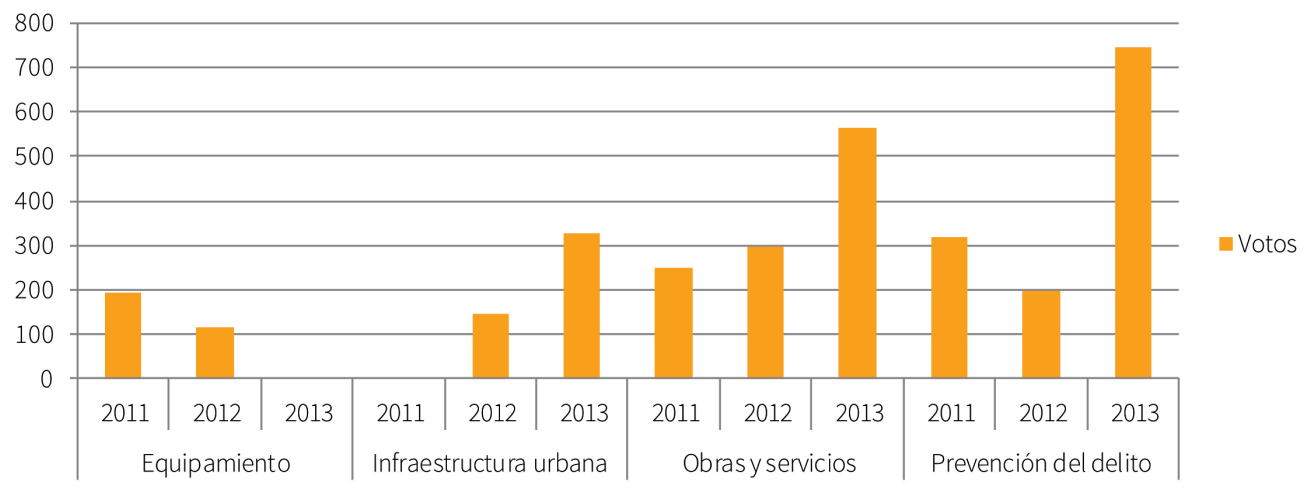

Fuente: elaboración propia con datos del IEDF.

A lo largo de las tres consultas destacan Prevención del delito y Obras y servicios; existe aquí una amplia zona de oficinas y servicios; en términos socioeconómicos la población mayoritaria es media-alta. 


\section{Gráfica 12. Milpa Alta}

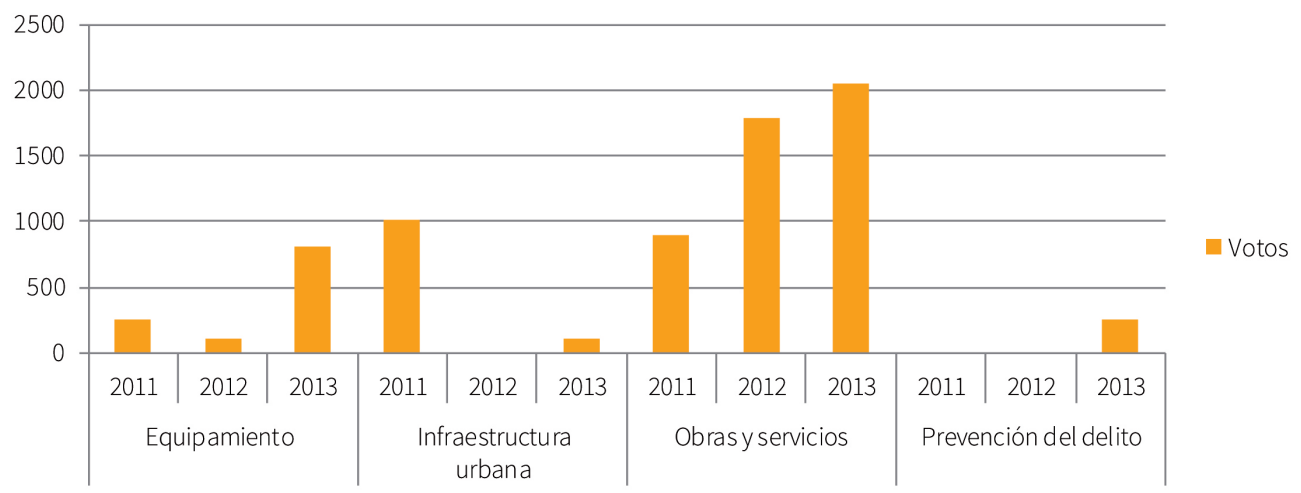

Fuente: elaboración propia con datos del IEDF.

Como constante en las tres consultas destaca Obras y servicios, con picos en Equipamiento e Infraestructura; en términos socioeconómicos, la población es mayoritariamente baja. Hay amplias zonas rurales.

\section{Gráfica 13. Tláhuac}

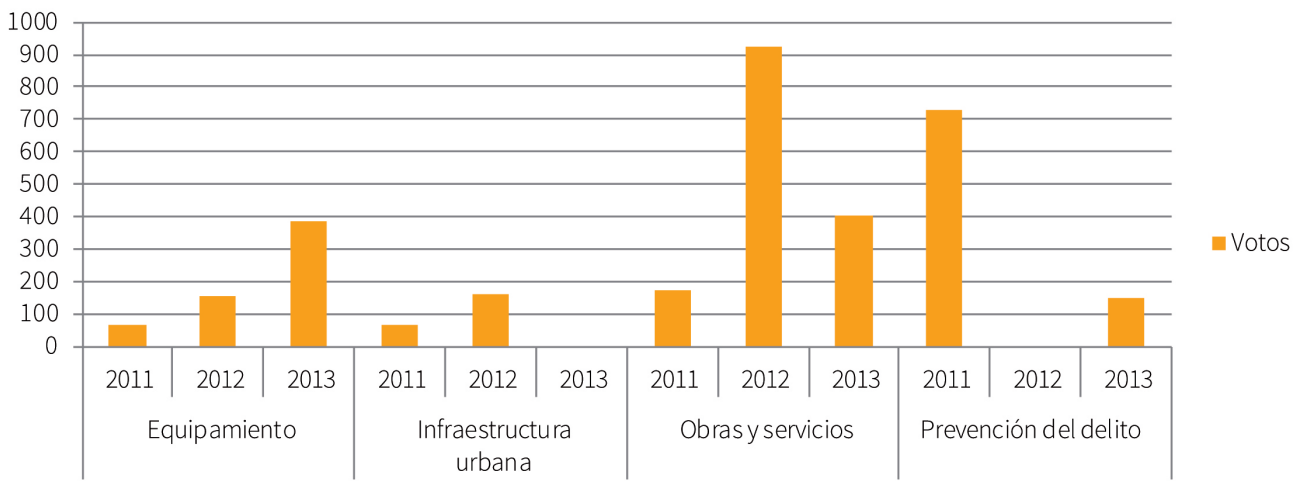

Fuente: elaboración propia con datos del IEDF.

Sobresalen Obras y servicios y Equipamiento, con un pico en Prevención del delito; en términos socioeconómicos, la población mayoritaria es baja. Hay amplias zonas rurales. 
Gráfica 14. Tlalpan

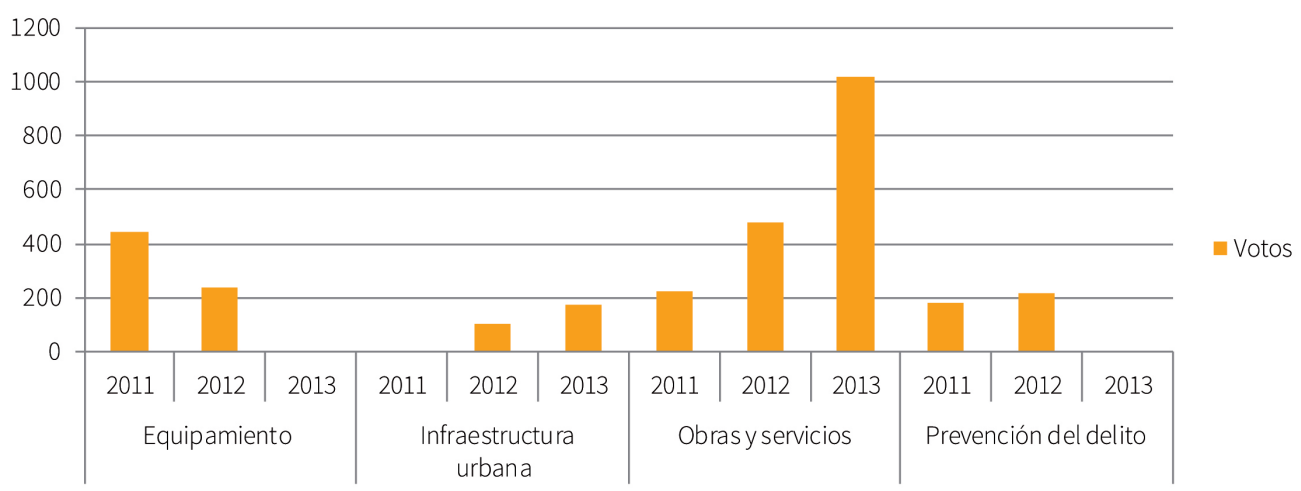

Fuente: elaboración propia con datos del IEDF.

Como constante a lo largo de las tres consultas se registra Obras y servicios, con un pico en Equipamiento; en términos socioeconómicos, la población mayoritaria es media-alta. Existen algunas zonas rurales.

Gráfica 15. Venustiano Carranza

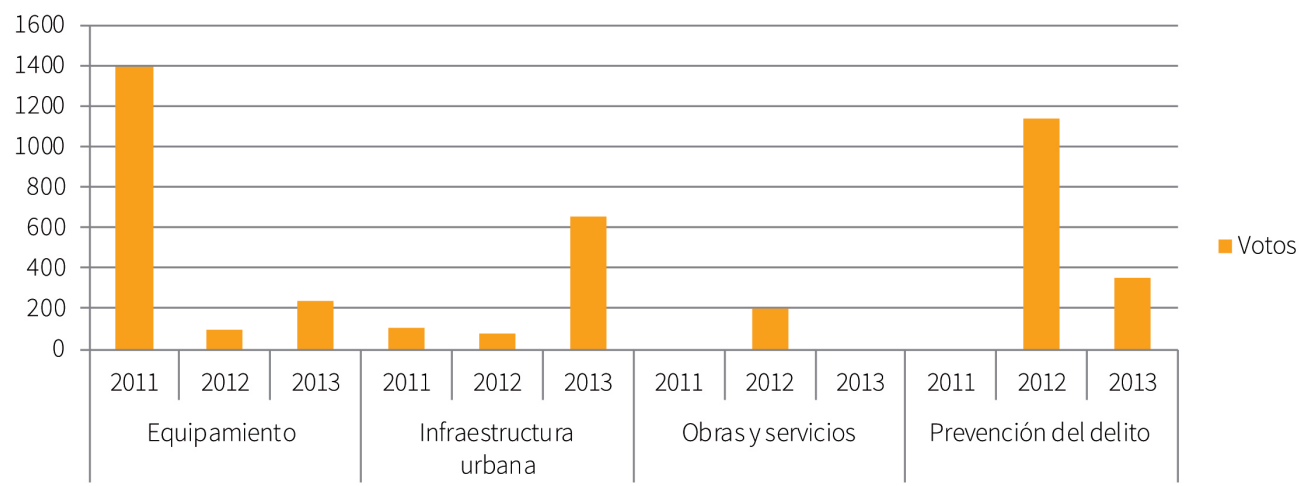

Fuente: elaboración propia con datos del IEDF.

A lo largo de las tres consultas se observan como constantes Equipamiento e Infraestructura, con un pico en Prevención del delito; en términos socioeconómicos, la población mayoritaria es media. 


\section{Gráfica 16. Xochimilco}

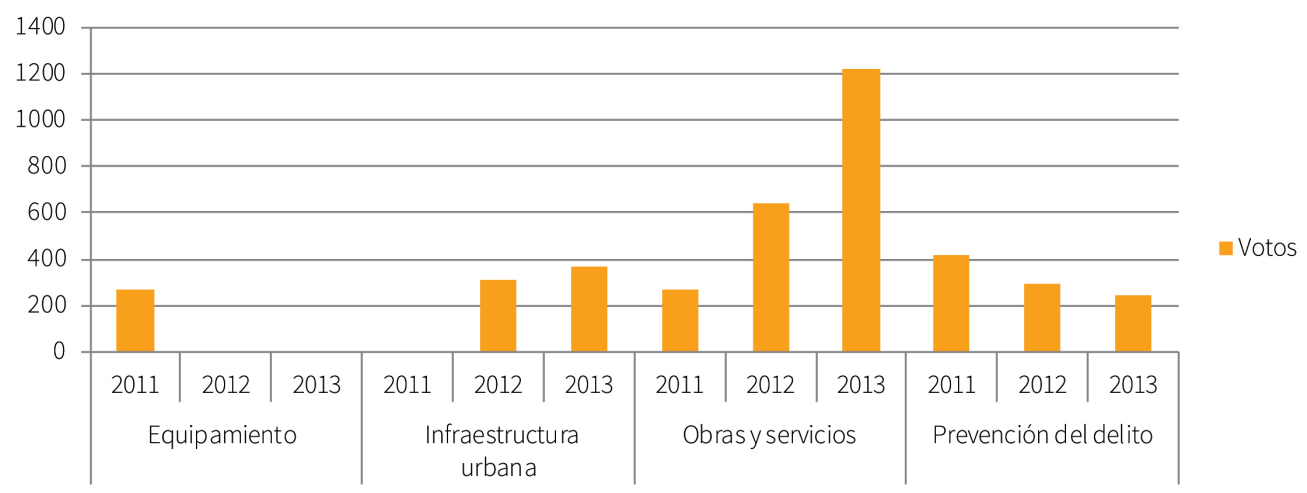

Fuente: elaboración propia con datos del IEDF.

A lo largo de las tres consultas se registran como constantes Obras y servicios y Prevención del delito; socioeconómicamente, la población mayoritaria es media-baja. Hay zonas rurales.

\section{Para la discusión}

La revisión en conjunto de las gráficas anteriores, permite establecer las tendencias siguientes:

- El rubro que más apoyo recibe es Obras y servicios; no obstante, las votaciones más altas se registran en el rubro Prevención del delito.

- Entre más elevados son los índices de desigualdad social entre la población mayoritaria de cada Delegación Política, mayores son las demandas en materia de Prevención del delito, así como en Obras y servicios. Asimismo, en los casos en que en la demarcación se concentra en zonas de oficinas o que entre sus actividades productivas predomina el sector terciario.

- En cuanto al rubro Prevención del delito, los proyectos específicos están ligados con acciones como colocación de luminarias y cercar espacios; en alguna medida como una respuesta de la ciudadanía a los problemas de inseguridad pública que prevalecen en el DF; no obstante, dichas acciones propician un mayor aislamiento de la población y menor convivencia social.

- En materia de respaldo a cada proyecto específico, cabe registrar que en promedio 199 personas avalaron cada uno, en tanto la Delegación Política con menor población es Milpa Alta con más de 130000, mientras en Iztapalapa viven más de 1800000 personas.

Finalmente, a continuación se establece un comparativo entre todas las Delegaciones Políticas durante los tres años de las consultas analizadas, sobre los rubros más votados, el cual contribuye a reforzar las observaciones anteriores: 


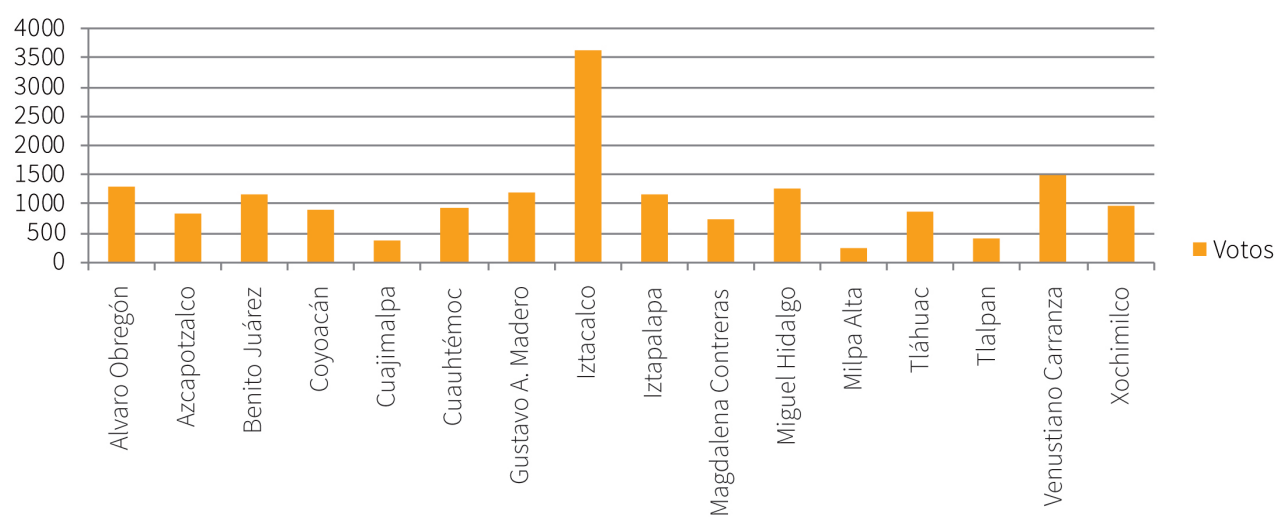

Fuente: elaboración propia con datos del IEDF.

Más de la mitad de las Delegaciones Políticas registran una votación semejante; en tanto los pocos casos que quedan abajo del promedio tienen población rural; si bien la Ciudad de México es mayoritariamente urbana, este dato permite inferir que el tema de la inseguridad es más un problema urbano.

Gráfica 18. Obras y servicios 2011-2013

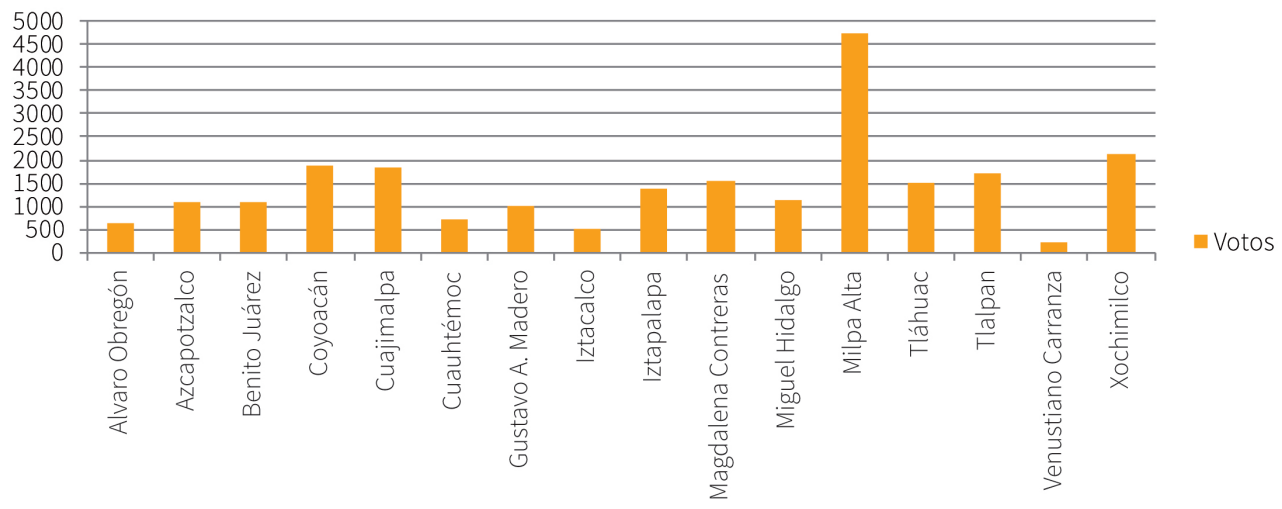

Fuente: elaboración propia con datos del IEDF.

Asimismo, al menos la mitad de las Delegaciones Políticas observan un promedio similar en la votación para este rubro, con algunos picos tanto en las zonas con población más pobre, como en las que se concentran zonas comerciales. 


\section{Conclusiones}

Inicialmente cabe subrayar el alcance limitado de los rubros que por ley son susceptibles de ser considerados por los residentes al momento de proponer proyectos específicos, para que en su caso sean votados por los ciudadanos en general, particularmente en cuanto a su impacto en factores estructurales que pudieran modificar la forma de gobierno y el ejercicio del presupuesto total de la Delegación Política respectiva; pues además los temas sometidos a votación son en esencia parte de las tareas ordinarias que debieran atender las autoridades delegacionales, sin necesidad de consultar a la ciudadanía si deben ser atendidas.

En ese sentido destaca que no se consideran rubros y por ende ni proyectos específicos de carácter estructural, que refieran aspectos como: uso del suelo; proyectos productivos comunitarios; programas de desarrollo social; seguimiento y evaluación de dichos programas, de manera especial los de prevención y combate al delito, ligados a la denuncia de servidores públicos que incurrieran en desvío o malversación de fondos públicos, entre otros.

Por otra parte, tomando en cuenta que de acuerdo con la Ley de Participación Ciudadana para el DF, solo se contempla el tres por ciento del presupuesto de cada Delegación Política para esta iniciativa, mismo que debe ser dividido entre el número de barrios, pueblos y colonias de cada demarcación, la cantidad que al final del reparto se pone a la consideración de los residentes es mínima, en comparación con las dimensiones de los problemas y de las necesidades que enfrenta cada localidad.

En cuanto a los avances de los proyectos votados, si bien de acuerdo con la información oficial de las Delegaciones Políticas a la fecha todos los proyectos tienen un avance del $100 \%$, cabe advertir que difícilmente no se cumplirá lo acordado o que algún funcionario público pudiera no atender lo comprometido, a la luz de lo que está en juego, como se ha comentado; no obstante, en algunos medios informativos de la ciudad capital se han ventilado presuntas desviaciones y omisiones, sin que hasta el momento hayan trascendido judicialmente.

Empero, habría que contrastar dicha información con la opinión de los integrantes de los Comités Ciudadanos, la cual hasta el momento ha sido imposible recopilar, dado el desinterés que han mostrado en responder una encuesta que les fue enviada; actitud que también han mostrado los partidos políticos, pues tampoco contestaron la respectiva encuesta. De modo que estas dos vertientes de opinión, abren líneas de investigación sobre el tema que deberán ser continuadas.

En cuanto al proceso inherente al mecanismo, es menester destacar la ausencia de una planificación a mediano plazo que comprenda metas en el corto y que conjugue lo sectorial con lo territorial; a fin de garantizar la continuidad de los proyectos acordados y rebasar la coyuntura; lo cual además de acrecentar el impacto social de los proyectos y de mantener el interés de los ciudadanos, abonaría a la formación de una cultura sobre la participación.

Tal vez el punto más endeble de este ejercicio participativo sea la escasa deliberación pública, inclusiva, extensa e intensa entre los residentes y de estos con las diferentes autoridades; lo cual inhibe el compromiso, demerita la calidad de las propuestas, limita la representación de intereses y poco abona a la generación de identidad y de significados compartidos entre los implicados.

Asimismo, se ha detectado que se carece de un sistema eficiente de información sobre las propuestas y de comunicación de los resultados. Así como de mecanismos que aseguren la transparencia y la rendición de cuentas alrededor del proceso en su conjunto. 
En alguna medida como resultado de los alcances del programa hasta el momento, habría que ubicar la baja participación de los residentes tanto para la conformación de los Comités Ciudadanos, encargados de dar seguimiento a los Presupuestos Participativos, como para la selección de los proyectos específicos para cada Delegación Política. De tal forma que esta iniciativa de participación debiera ser colocada más en un ámbito simbólico que concreto, como históricamente ha venido sucediendo con los mecanismos para la participación ciudadana que se han impulsado en Ciudad de México, indistintamente del partido en el gobierno.

\section{Referencias}

1. Águila, R. (mayo-agosto, 1996). La participación política como generadora de educación cívica y gobernabilidad. Revista Iberoamericana de Educación, 12,31-44.

2. Álvarez, L. (1997). El proceso participativo y la apropiación del espacio público en el Distrito Federal. En L. Álvarez (Coord.). Participación y democracia en la Ciudad de México. (pp. 131-149). México: La Jornada Ediciones-Centro de Investigaciones Interdisciplinarias en Ciencias y Humanidades/UNAM.

3. Álvarez, L. (2006). Actores sociales, construcción de ciudadanía y proceso democrático en la Ciudad de México. En L. Álvarez, C. San Juan y C. Sánchez (Coord.). Democracia y Exclusión. Caminos encontrados en la Ciudad de México. (pp. 47-65). México: CIICH/UNAM-UAM/Azcapotzalco-UACM-INAH-Plaza y Valdés.

4. Barber, B. (1998). Democracia fuerte. En R. Águila et al. La democracia en sus textos. (pp. 281-296). Madrid: Alianza Editorial.

5. Berlin, I. (1988). Cuatro ensayos sobre la libertad. Madrid: Alianza.

6. Blanco, I. (2002). Presupuestos participativos y democracia local: una comparación entre las experiencias brasileña y española. Conferencia presentada en el VII Congreso Internacional del CLAD sobre la Reforma del Estado y de la Administración Pública, Lisboa, Portugal.

7. Bolos, S. (2006). Los movimientos sociales, actores de la democratización en la ciudad. En L. Álvarez, C. San Juan y C. Sánchez (Coord.). Democracia y Exclusión. Caminos encontrados en la Ciudad de México. (pp. 73-88). México: UNAM/CIICH-UAM/Azcapotzalco-UACM-INAH-Plaza y Valdés.

8. Cansino, C. (2006). Calidad de la democracia. Paradojas y contradicciones. En L. Álvarez, C. San Juan y C. Sánchez (Coord.). Democracia y Exclusión. Caminos encontrados en la Ciudad de México. (pp. 15-30). México: UNAM/CIICH-UAM/Azcapotzalco-UACM-INAH-Plaza y Valdés.

9. Cunill, N. (1991). La participación ciudadana. Caracas: CLAD.

10. Fernández, P. (1998). El Distrito Federal: reto a las estructuras de control. En E. Gutiérrez (Coord.). El debate nacional 2. Escenarios de la democratización. México: Diana-FCPyS/UNAM.

11. Franzé, J. (1996). El discurso del malestar civil: la crisis política como crisis de lo político. En A. Porras Nadales (Ed.). El debate sobre la crisis de la representación política. (pp. 119-148). Madrid: Tecnos.

12. Held, D. (2002). Modelos de democracia. Madrid: Alianza.

13. Kitschelt, H. (2001). Panoramas de intermediación de intereses políticos: movimientos sociales, grupos de interés y partidos a comienzos del siglo XXI. En R. Máiz (Coord.). Construcción de Europa, Democracia y Globalización Vol. 1. (pp. 361-386). Santiago de Compostela, España: Universidad de Santiago de Compostela.

14. O’ Donnell, G. (1998). Accountability horizontal. La Política, 4, 161-188. 
15. Sánchez, J. (2007). Lo que el brillo electoral oculta: la representación como problema teórico y práctico del cambio político en el México actual. En F. Castaños, J. Labastida y M. López (Coord.). El estado actual de la democracia en México. Retos, avances y retrocesos. (pp. 201-233). México: UNAM/IIS.

16. Sandoval, G. (2006). Atención ciudadana o participación ciudadana ¿de quiénes?, ¿para quiénes? En L. Álvarez, C. San Juan y C. Sánchez (Coord.). Democracia y Exclusión. Caminos encontrados en la Ciudad de México. (pp. 345-360). México: UNAM/CIICH-UAM/Azcapotzalco-UACM-INAH-Plaza y Valdés.

17. Warren, M. (2001). Democracy and association. New Jersey: Princeton University Press.

18. Zermeño, S. (2004). La participación ciudadana bajo los gobiernos perredistas del Distrito Federal (19972003). En A. Ziccardi (Coord.). Participación ciudadana y políticas sociales en el ámbito local. (pp. 145-166). México: IIS/UNAM-INDESOL-COMECSO.

19. Ziccardi, A. (1998). Gobernabilidad y participación ciudadana en la ciudad capital. México: IIS/UNAM.

20. Ziccardi, A. (2006). Ciudades, asociaciones y decisiones públicas. En L. Álvarez, C. San Juan y C. Sánchez (Coord.). Democracia y Exclusión. Caminos encontrados en la Ciudad de México. (pp. 91-107). México: UNAM/CIICH-UAM/Azcapotzalco-UACM-INAH-Plaza y Valdés. 